ISSN: 2162-3104 Print/ ISSN: 2166-3750 Online

Volume 8, Issue 1 (2018), pp. 375-388

(C) Journal of International Students

$\mathrm{http}: / /$ jistudents.org/

doi: $10.5281 /$ zenodo. 1134315

\title{
Beyond Culture: Helping International Students Avoid Plagiarism
}

\author{
Soni Adhikari \\ Stony Brook University, United States
}

\begin{abstract}
With the rapid increase in the number of international students from different academic backgrounds around the world, college and university teachers in the West find it harder to understand the many and complex reasons when these students plagiarize or use sources ineffectively. Reviewing relevant literature, I first make a pedagogical analysis of student plagiarism then show why teachers should shift focus from traditional views about cultural difference toward a multidimensional understanding of plagiarism. I conclude by recommending pedagogical strategies to help students to adjust to the new academic system rather than "policing" their activities and undermining their confidence.
\end{abstract}

Keywords: academic backgrounds, cultural change, international students, plagiarism

The total number of international students in the United States reached nearly a million in the fall of 2015 , with a $10 \%$ increase from the previous year (IIE, 2015). From an educational perspective, the most striking aspect of the trend is that the largest and fastest growing groups of students also come from academic cultures that are distinct from that of the United States. Over 70 percent of the international students come from Asian countries, primarily from China, South Korea, and India in the US (IIE, 2015). According to Chen and Ullen (2011), "Due to cultural differences, international students . . . may encounter cultural shock when facing instructional methods, assignment requirements, and writing styles that are 
different from what they experienced in their home countries" (p. 209). Most teachers interpret this situation as potentially increasing chances of plagiarism among international students: if there are more students coming from cultures that view knowledge and originality differently, then more students are likely to plagiarize. However, those of us who have worked with international students know that most of them either already know about the concept of plagiarism or learn about it quickly. They also learn about the consequences from their peers and from instructor, and most of times, these students plagiarize unintentionally rather than trying to be dishonest. Instead, international students may not have the practical skills needed to properly document and engage sources, may not be able to develop original positions and ideas because they struggle with content or context, and may make mistakes because they cannot manage time or information in the research and writing process. International students, as well as their domestic counterparts, also fail to distinguish between responsible use of sources and unacceptable ones because new technologies are making it harder for everyone to do so. As the notion of intellectual property continues to evolve, plagiarism is becoming more multifaceted and complex, whether it is intentional or not.

In this article, I argue that teachers can best address plagiarism by looking beyond cultural background for the many possible causes of student plagiarism. They can prevent and address plagiarism pedagogically, especially by helping students understand rules for documentation of written texts in terms of how knowledge and learning are defined in the new academic culture. Furthermore, instead of trying to figure out whether students making mistakes are honest or dishonest, it is much more important to consider their understanding of originality, their ability to generate new ideas on given topics, the level of their citation skills relative to the demands, and such other factors that increase the chances of unintentional plagiarism and must be addressed pedagogically. I first briefly review relevant scholarship from a variety of disciplines (including Writing Studies, Applied Linguistics, Sociology, and the Sciences). Then I suggest that teachers can tackle plagiarism if they understand it less as a cross-cultural issue and more as a set of challenges created when students encounter new academic practices, conventions, and assumptions in a new society. Even when students "know" about plagiarism and make honest efforts, they may make mistakes because they are new to academic practices and do not yet have the sophistication of skills in writing, researching, and presenting ideas demanded by a class. I conclude the article by making a number of pedagogical recommendations for better addressing plagiarism. By 
critiquing conventional tendencies to generalize cultural differences (which can lead to stereotyping of students as ignorant about originality or dishonest when they don't meet the standards), I urge teachers to move toward a multidimensional understanding of plagiarism.

\section{LITTLE "c" VERSUS BIG "C": BEYOND GENERALIZED CULTURES}

Traditional scholarship on plagiarism not only focuses on cultural difference but also assumes that other cultures do not know or value originality. Accordingly, international students plagiarize because their culture did not teach them about plagiarism. From this perspective, teachers must teach about plagiarism as a cultural phenomenon, situating it in the larger cultural context and unpacking ideas underlying the proper use of sources. This view of plagiarism defines culture too generally, a view that Herron, Cole, Corrie and Dubreil (1999) call the big "C" culture. A more productive view of plagiarism is to define it in terms of specific academic practices, using the little "c" view of culture that allows us to focus on culture as constituting specific practices and processes. Viewing plagiarism in terms of specific conventions and practices of borrowing and using other people's ideas in specific academic contexts, disciplines, and courses helps us focus on the "process" rather than try to teach about the broader "products" of a culture, such as history and civilization, as well as tangible products such as music and art in general (Herron, Cole, Corrie, \& Dubreil, 1999; p. 519). Focusing on "cultural practices that subsume patterns of behavior including social knowledge of a language system, (p. 519)" especially as translated into practical academic skills can help us both understand and address plagiarism much better.

Shifting the view of plagiarism from the perspective of big $\mathrm{C}$ culture towards that of small c can prompt teachers to take responsibility for teaching what students have not yet learned to giving them sufficient time and practice to develop the habit and skill for engaging sources. Instead of othering students based on how we believe their culture defines plagiarism and intellectual honesty, we can focus on teaching them practical skills that they need to learn. In an article in the Chronicle Review, Howard (2001) urged teachers to calm down and get back to the business of teaching. Moreover, she argued when teachers try to "police" plagiarism, they severely undermine the "friendly relationship" with their students (Howard, 2001). With international students, it is particularly important to focus on helping them learn specific skills rather than just informing them about the 
larger idea, shifting the focus from knowledge/awareness to skills and then to the process of finding and using others' ideas. The approach of "policing" can undermine confidence and interest in writing among international students because many of them start with lower levels of mastery of language, content, and rhetorical strategies and need motivation to catch up with the rest of the class in the various areas. When teachers start by assuming that students are more likely to plagiarize because they don't know "about" plagiarism or are more likely to "cheat," they are quicker to turn students to disciplinary committees or penalize themselves (rather than teach them the skills they are yet to learn). So, as Howard stated, it is really important for teachers to work like "mentors" and adapt pedagogy to accommodate international students' need to translate abstract concepts like plagiarism into practical skills.

Another benefit of taking a small $\mathrm{c}$ view of plagiarism is that it facilitates a dynamic view of originality and plagiarism: it allows us to consider that the practices (and, more gradually, values) that embody these concepts change over time, also allowing us to consider the influence of technology, advancement of knowledge, and so on. Sapp (2002) argued that a redefined understanding of "plagiarism" is becoming inevitable and the current one will be considered, in the words of Riegle (1998), "left-over from a more hegemonic, less-global time" and those arguing for a static and essentialist view will be considered self-serving. Scholars like Sapp argued that as current notions of intellectual property become more and more obsolete with every generation of technology, teachers need to move toward an international and intercultural understanding of plagiarism and develop related and appropriate pedagogical strategies. He added that writing teachers "must ... realize that often pedagogical rather than judicial responses are appropriate" (p. 14). Sapp also suggested writing instructors to re-examine the traditional way of judging and condemning the students' cheating behaviors. Similarly, another scholar from Writing Studies, Lyon (2009) challenges the traditional view about the ownership of writing by situating writing and language in the world of international education. While using the discourse of plagiarism "to examine how cultur[al] forces and assumptions about the nature of speaking and writing complexly interact in an international classroom," she urges teachers to not generalize nonWestern student "as deficit and in need of redemption" (p. 224). Lyon's analysis of how and why any student may plagiarize helps us to view citation in specific contexts and as it makes sense to particular students. As such, a dissertation writer who is trying to develop her major thesis or an undergraduate student who is writing his literacy narrative may be more 
engaged in their ideas than a student who does not understand an assignment, has serious challenges in language, has extremely high parental or financial pressures, or is afraid of losing the visa status due to failure. This is not to suggest that the latter group of students be excused or treated leniently, but it is to emphasize the importance of understanding their particular situations (more than their home cultures) and supporting them accordingly.

Let me contrast the two approaches I mentioned earlier with another example. About three decades ago, Matalene (1984) recounted her experience of trying to teach academic writing to students in China, showing how students there did other things well but did not understand originality or plagiarism and did not cite sources. Matalene said that "for the Chinese writer, invention means doing it the way it has been done" (p. 794), unlike the Western concept of originality as in Ezra Pound's "make it new." She further explained that Chinese writers develop ideas in relation to "some fundamental principles of the culture which contains them" (p. 794). Learning by imitation and memorizing the whole textbook by heart, reciting the whole history in the form of folklore is a very common practice of literacy and writing in many Eastern academic systems. The problem with Matalene's approach is that it seeks to find all the "cultural" differences and induces generalizations, describing differences in academic practices as embodying fundamental cultural differences. The other, little "c" approach looks at the particular ways in which teaching and learning is done in another culture in educational and pedagogical terms; it looks at Chinese students as having a certain set of skills in which some things are useful and others are missing. As such, an American teacher should identify what the student needs and starts to teach and provide students ample opportunities for practice. The teacher should realize that students take time to develop the many and complex skills that a new academic system demands.

Focusing on seemingly fundamental differences between cultures can also lead teachers to impose one culture over another, instead of teaching new academic skills that are demanded by a higher level of education, a different discipline, or simply a course that has specific expectations. In "Speak for yourself: Power and hybridity in cross-cultural classroom," Williams (2003) describes the difficulty he faced when trying to teach writing to students from different national background at an American school in the United Kingdom. Reflecting on the failure of good-faith efforts that he made to change students' worldview about originality, Williams cautions against using teaching original writing as a tool of ideological assimilation. He remembers a student from Pakistan who apparently refused 
to cite sources properly: he would teach the student how to cite sources and "she would assure [him] that she understood" how to, but then "proceed in the next draft to provide one or two citations in a paper filled with information from other sources" (p. 589). I have faced similar challenges in my own teaching, which typically turn out to be due to lack of practice rather than lack of understanding. As the student revises the writing, further practices citation in class, and works on subsequent essays, he or she gradually cites more correctly and effectively.

Focusing more on academic practices than on cultural differences, and more on skills than on understanding, also encourages teachers to shift focus from students' honesty to their own teaching. So, for instance, instead of turning students in for judiciary action, teachers may assess what they have and haven't taught in class yet. As Canagarajah (2002) stated in "Contextualizing academic writing," norms of citation are different in different countries/cultures. As such, scholars who want to publish in different contexts need to understand the expectations and practices of those contexts; those practices may reveal broader cultural issues and belief systems, but in order to be successful, one must show them in practice. In the same way, international students need particular skills more importantly than just becoming aware of the new academic and social culture in the abstract. Because conformity to ethical standards and exhibiting strong professionalism is expected among all professions (Doss et.al. 2016; p. 547), teaching about the idea of originality and properly citing the sources in a new academic setting becomes an important subject to discuss in writing class; but unless discussions are turned into practice, students may still commit plagiarism, prompting teachers to turn them in. International students can best learn multiple worldviews (or big "C" culture) about originality by learning multiple skill sets (small "c" culture).

Scholars of library services have also paid a lot of attention to how and why international students across the disciplines commit plagiarism. However, even when they rightly identify the gaps in students' skills and understanding, most institutions focus more on why students plagiarize than on how they could avoid it. For example, Chen and Ullen (2011) reported the finding of survey conducted at Lancaster University in the United Kingdom that many students from Asian countries arrive with skill sets that are different from Western universities. Their study identified the challenge as a lack or insufficiency of skills, but the solution the authors developed is problematic: they created workshops focusing on "information" and lectures about plagiarism. One of the students who attended the workshop, which was a part of the study, said: “... with that workshop I got more information 
about the standard of plagiarism and what is called plagiarism here. It's not the thing that we call plagiarism in our country, some of it" (p. 223). Using qualitative and quantitative research methods, the authors studied a range of complex issues focusing on cultural differences; among other things, they found that many Asian students were confused not only about when and how to cite but also "why" to cite. Unfortunately, when students plagiarize, institutional solutions fail to provide students the "practice" they need and instead give them lectures and threaten them with punishment. The authors found that some students copied from texts because they did not have anything new to say, others didn't understand the texts that they studied, and yet others plagiarized because their instructors cared most about (and rewarded) their grammatical errors and did not take the time to teach them how to improve their work (p. 225). In all these cases, the root cause is educational and not cultural, and even to the extent it is cultural, its solution lies in teaching skills not in "info sessions."

Quite often, students plagiarize in spite of their knowledge about plagiarism and its consequence. This means that teachers need to focus on causes that go beyond knowledge and awareness. Adiningrum and Kutieleh (2011) report the results of their study among Indonesian students. All of the Indonesian students "recognized that in order keep up with international academic standards, avoiding plagiarism should be addressed in Indonesian universities" (p. A-94). But when it comes to practice in the local context, those students did not agree that the same standards are possible or necessary to implement. This means that students who come to the United States from westernized academic systems are likely to understand what plagiarism is. Teachers may need to build on that awareness in order to help students practically meet the tough standards of citation and documentation of sources in U.S. higher education.

According to the Open Doors Report of the Institute of International Studies, two third of the total of 974,000 international students come from Asia and the Middle East (IIE) where regular teaching/learning involves less writing in general and less source-based writing in particular. In most of these places, assessment is done through final examinations. So, whether or not students from these countries know about plagiarism, taking a position and using citations can be challenging. The solution to this challenge is not only citing other writers' ideas correctly but also learning new strategies for responding to other writers. Introna and Hayes (2007) report a study done among graduate international students. They showed that "plagiarist practices are often the outcome of many complex and culturally situated influences" (p. 213). Indeed, it is not just pedagogically effective but also 
ethical to keep in mind what skills students may have already learned and what they need to learn.

In a study among engineering students in Swedish universities, Gunarsson, Kulesza, and Pettersson (2014) found that even at the graduate level, international students from many cultures are not yet able to meet the expectations of Western universities. But the closer study of students' challenges revealed that even advanced students in engineering "still need basic education on how to cite and reference properly" (p. 416). One of the challenges students face is to determine what is common knowledge and what counts as original. While this may look a matter of general understanding, in actual writing, it boils down to demarcation of one's ideas against ideas from outside sources. As cultural outsiders, international students may fail to clearly indicate the boundaries of their voice against those of others because this is a skill they are yet to learn.

It is true that the idea of "originality" (upon which the concept of plagiarism depends) is less familiar in some societies than others. In traditional societies, knowledge can be deemed as being "out there" rather than as a commodity that individuals own. Learners in such societies may not believe as strongly that they can or need to present "new" ideas as they do in the more advanced "knowledge economies." For this reason, "Interviews with international students indicate that some students may arrive at an American university with little, if any, understanding of the concept of plagiarism" (Amsberry, p. 38). But even for students who are unfamiliar with the concept, the solution is not mere awareness. If students do not know that it is dishonest to copy or imitate established writers, they can be informed about this. The problem is that the information only solves a small problem and leaves a lot more to be done.

For instance, I grew up in an academic system where students were expected to memorize ideas from textbooks in order to write in the examination; it did not matter to us who the authors of the textbooks were. When students reached the end of their master's degrees, they were required to write the research thesis, a task that required proper citation for the first time. Because citation skills were not taught as part of any course, students' writing did not stand up to the standards of research-based writing in countries like the United States, and many students might have inadvertently committed plagiarism. In fact, teachers did not demand very high standards either, as long as students demonstrated that they have read extensively and used substantive support for their argument. So, when a student from a background like that joins a graduate program in the United States, he or she will face challenges with citation not so much due to "cultural difference" as 
due to having never learned specific academic skills required in the new place.

Finally, there is a need to use the best understanding about plagiarism from all the scholarship that we can find because the use of convenient technology instead of good pedagogy is becoming an increasingly common practice. For example, electronic detection systems may not distinguish between properly cited sources and plagiarized writing, not to mention their failure to distinguish between rookie mistakes and intentional plagiarism. The tools may be convenient for teachers and administrators but they may not be meaningful from the learners' perspectives. Because the applications can be faulty as well as easy to misuse, they "could lead to the unfair and unjust construction of international students as plagiarists" (Introna \& Hayes, 2007, p. 2). It is for this reason that I urge teachers to look beyond their discipline and local context for better understanding how to help international students understand mainstream academic practice. As Fass-Holmes (2016) stated, teachers must focus "on teaching and learning rather than students' behavior and character" (p. 17). He suggests that we "facilitate data-driven pedagogical, administrative, and/or programming decisions for controlling international students' cheating and for promoting their retention and graduation rates" (p. 2) and also focus on teaching more than anything else. In short, the small $\mathrm{c}$ approach described above would prompt teachers to take responsibility for teaching practical skills rather than putting students in assumed general categories of big $\mathrm{C}$ culture.

\section{RECOMMENDATIONS FOR COLLEGE TEACHERS}

There are fairly simple things that teachers can do to help international students practically avoid plagiarism. We can start by becoming aware of the assumptions and superficial ways in which plagiarism and academic integrity are addressed when it comes to international students. Based on this understanding, teachers can rethink the traditional approaches, shift the focus from cultural understanding to academic skills and from "policing" to teaching (Howard, 2001). These shifts can help us develop new ways of teaching that will more directly target where international students face challenges, instead of viewing them as a single group with the same challenges.

Teachers should teach international students the concept of ownership of ideas by practically showing the importance of "academic" honesty (Thompson et al., 2017). If a student can't see how "ideas" can be 
stolen, the first thing a teacher needs to do is to illustrate cases where ideas are people's means of living, their intellectual property and professional achievements. Similarly, if a student is yet to learn where and when people mind when someone takes their ideas without asking, teachers can illustrate cases of ethical responsibility toward others' ideas as well.

Teaching skills for citing academic source cannot be separated from teaching students how to generate new/original ideas in their own voice; one effective method of doing both at the same time is to teach annotation skills to students. To be an expert in any academic discipline means to have substantive knowledge about the facts, realities and perspective that the knowledge community has developed and shared. The notion of writing "paper" by proposing a new argument or perspective, instead of demonstrating knowledge by using others' ideas, is a new skill in modern education and professions - rather than a feature of one culture and not others. For all these reasons, teachers should spend the time to teach students practical skills that will help them face new challenges of writing in in today's world. They should teach the rules of citation before penalizing and putting them in career damaging legal complication just for not being able to cite sources properly. Teachers must also distinguish between serious and superficial forms of plagiarism: "[a]ccidentally omitting a set of quotation marks is not the same as submitting a downloaded paper" (Howard, 2001).

Teachers can best help international students learn the skills for avoiding plagiarism if the classroom environment is friendly and motivating. Hudley and Mallison (2014) pointed out a former middle school language arts teacher who described how he was able to connect with his students and begin to overcome cultural divides when he realized that it was necessary to understand not only his students' backgrounds but also his own (p. 45). The teacher described how he had to change his habit of speaking too fast to speaking more slowly and the way he developed interaction with his students by sharing the background of him growing up in order to make a productive learning environment (p. 46). The writers further added, "by sharing their stories, educators and students can bridge difference and build connections" (p. 45). This kind of sharing and bridging the different literary practices between the international students and the teachers can help them share what Lippi-Green calls the "communicative burden" (Hudley \& Mallinson, 2014, p. 47). Communicative burden means the difficulty that speakers/writers and listeners/readers face with communicating their ideas, so one side can make it easier for the other by understanding the difficulty and trying to alleviate it. This burden is related to the verbal act in which the 
speaker and the listener try to mutually understand each other; it goes largely unnoticed in the case of speakers who share the same language. In the context of international students, learning about each other's academic backgrounds can help both learning and teaching. In contrast, "[m]aking value judgments without proper orientation to cultural differences discourages students and faculty alike and can lead to adversarial positions" (Thompson et al., 2017, p. 150). Because the concept of plagiarism is complex and it also varies by place, discipline and even instructor, teachers should spend the time to unravel that complexity for new students using concrete examples and giving students ample opportunities to practice. One of the best ways to teach the complex concept of plagiarism is to show students samples of research papers. Teachers can analyze and show them the textual features of the samples from their disciplines. This will help the students to reflect on the issues and debate that they have heard outside classroom. Then students can gradually start paying attention to some of the essential features of research process including the correct way of citing sources. While making connections to writing by analyzing the real purpose, audience, conventions, genre and style, inexperienced writers can also learn to cite the authors by looking at what Laura Robb calls "mentor texts" (or sample texts provided by or used as teaching materials by teachers).

Teachers should provide international students extra consultations and exercises for learning how to cite correctly. Teachers can also show them how to use manuals for citation, share online resources (for example, Purdue OWL), refer to librarians and encourage them to attend workshops and seminars, as well as help students practice citation in class activities. Letting students work in groups can help them better conduct research writing and use standard citation practices. It is equally important to help the students see the relationship between their idea and their sources as a way to avoid plagiarism. If the students are taught practical skills (such as how to use signal phrases, reporting verbs, in-text citation list of works cited, paraphrasing and summarizing), they can improve their writing and write more originally. Focusing on practical skills helps them to develop the feeling that they can prepare research projects in order to engage in scholarly activities addressing audience outside the classroom. Instead of reporting students after they submit their assignments, teachers should be friendly and supportive in the process of teaching writing. They should create a learning environment to accommodate the students who have come from different cultural and educational backgrounds. Moreover, they need to help students understand the benefit of citing source properly and ways to prevent plagiarism significantly ahead of submitting the assignment. 
Teachers should realize that when they blame students for plagiarizing, they too ironically share that blame to the extent that they have not yet taught students how to avoid plagiarism.

Providing guidelines and reference materials can also help students with effective and correct citation. From the findings of a study on plagiarism, Bista (2011) stated that "many students do not know what plagiarism is due to complex cultural differences as well as the past learning and teaching styles of their home country," further highlighting that international students "must receive direct, explicit instruction concerning plagiarism in the preparation of research papers as well as course work" (p. 167). Explicit instruction and encouraging academic environment can go a long way in helping international students fill often large gaps in their academic skills, catching up to the demands without fear of making mistakes.

\section{CONCLUSION}

Plagiarism is not just an abstract cultural concept but it is understood almost universally. The argument that it is a Western concept that students from non-Western backgrounds do not understand or appreciate is increasingly problematic. When international students fail to cite sources properly and effectively, it is usually because they don't know "how" to do so; they haven't yet learned specific practices and skills for taking positions in relation to existing knowledge and using that knowledge to support their ideas. The challenges with language, writing skills, understanding of subject matter or social context, and so on that many international students face prompts some of them to take short cuts in their learning and writing. When this happens, teachers must first resort to pedagogical solutions, asking if the student has the skills; beyond skills, teachers can and should also consider external factors, such as lack of time and stress, that may have led the student to make a poor decision. When students with widely different skill sets and educational backgrounds fill our classrooms, challenges certainly increase. But we cannot just blame it on the Chinese or Indian culture when students who came from there do not yet know how to research, write, and cite effectively. Students who don't have expected skills may quite well be domestic students. For all students, teachers need to rethink traditional approaches, shifting focus from "policing" to teaching (Howard, 2001), developing new ways of teaching that are helpful to international students.

In short, while "culture" shapes academic skills and practices and broader ideas of culture may need to be discussed when teaching specific 
skills, the teaching of academic skills must be the primary focus of helping international students to avoid plagiarism while learning research and writing skills. When students understand that citing and quoting properly builds their credibility with readers, they start to learn how to do so practically. And while they have come to a different country/culture and want to learn about it, the best way to do so is to break it down into specific academic skills and to help students gradually master them-focusing on the small "c" of practice as a means of understanding the big " $\mathrm{C}$ " of a new culture as well.

\section{REFERENCES}

Adiningrum, T. S., \& Kutieleh, S. (2011). How different are we? Understanding and managing plagiarism between East and West. Journal of Academic Language \& Learning, 5(2), A88-A98.

Amsberry, D. (2010). Deconstructing plagiarism: International students and textual borrowing practices. The Reference Librarian 51, 31-44.

Bista, K. (2011). Academic dishonesty among international students in higher education. In Miller, J. \& Groccia, J. (Eds.). To improve the academy: Resources for faculty, instructional and organizational development ( $\mathrm{pp}$. 159-172). San Francisco, CA: Jossey-Bass.

Canagarajah, S A. (2002). A geopolitics of academic writing. Pittsburgh, PA: University of Pittsburgh Press.

Chen, Y.-H., \& Van Ullen, M. K. (2011). Helping international students succeed academically through research process and plagiarism workshops. College and Research Libraries 72(3), 209-235.

Doss, D.A, Henley, R., Gokaraju, B., McElreath, D., Jackson, H.L., Hong, Q., \& Miller, L. (2016). Assessing domestic versus international student perception and attitudes of plagiarism. Journal of International Students, 6(2), 542-565.

Duff, A H., Rogers, D. P., \& Harris, M. B. (2006). International engineering students: Avoiding plagiarism through understanding the western academic context of scholarship. European Journal of Engineering Education, 31, 6, 673-681.

Fass-Holmes, B. (2016,). International students reported for academic integration violations: Demographics, retention, and graduation. Journal of International Students, 6(4), 933-955.

Herron, C., Cole, S. P., Corrie, C., \& Dubreil, S. (2000). The effectiveness of a video-based curriculum in teaching culture. Modern Language Journal, 83(4), 518-533.

Howard, R. M. (2001 November 6). Forget about plagiarism: Just teach. The Chronicle of Higher Education. Retrieved from http://chronicle.com/ $\mathrm{prm} /$ weekly/v48/i12/12b02401.htm 
Charity, H. \& Mallison, C. (2014). We do language: English language variation in the secondary English classroom. New York: Teachers College Press.

Institute of International Education (2015). Open Doors report on international educational exchange. Retrieved from http://www.iie.org/opendoors

Introna, L., \& Hayes, N. (2007). Plagiarism detection systems and international students: Detecting plagiarism, Copying or learning? Idea Group Publishing (Archival material).

Lyon, A. (2009). "You fail": Plagiarism, the ownership of writing, and transnational conflicts. College Composition and Communication, 61(2), 222-239.

Matalene, C. (1985). Contrastive rhetoric: An American writing teacher in China. College English, 47(8), 789-808.

Riegle, R. (1998). The death and rebirth of plagiarism: Ethics and education in the infosphere. Retrieved from http://www.coe.ilstu.edu/rpriegle/wwwdocs/ plagiari.htm

Robb, L., \& Burke, J. (2010). Teaching middle school writers: What every English teacher needs to know. Portsmouth, NH: Heinemann.

Sapp, D. A. (2002). Toward an international and intercultural understanding of plagiarism and academic dishonesty in composition: Reflections from the People's Republic of China. Issues in Writing, 13(1), 58-79.

Thompson, L. W., Bagby, J. H., Sulak, T. N., Sheets, J., \& Trepinski, T. M. (2017). The cultural elements of academic honesty. Journal for International Students 7(1), 136-153.

Villiams, B. T. (2003). Speak for yourself? Power and hybridity in the cross-cultural classroom. College Composition and Communication, 54(4), 586-609.

SONI ADHIKARI is a lecturer of writing and rhetoric at Stony Brook University. A former instructor of English language and literature from Nepal, Adhikari focuses on global and transnational issues in her teaching and studies of college-level writing. Email: soni.adhikari@stonybrook.edu 